\title{
Critical stability conditions in skimmed milk crossflow microfiltration: impact on operating modes
}

\author{
Geneviève GÉSAN-GuIZIOU*, Georges DAUfIN, Evelyne BoYAVAL \\ Laboratoire de recherches de technologie laitière, INRA, \\ 65 rue de Saint-Brieuc, 35042 Rennes Cedex, France
}

\begin{abstract}
There exists a critical ratio (convection towards the membrane/erosion) in crossflow microfiltration, MF, below which there is no marked fouling by colloidal particles and above which performance are altered: sharp increase of fouling, reduced operating time, large decrease in permeability and solute transmission. This paper outlines the impact of the critical ratio on skimmed milk MF processing (separation of casein micelles from the soluble proteins) and gives objective elements (taking into account the critical ratio) for the selection of start-up procedures and stationary modes of operation: controlled transmembrane pressure or permeation flux; "static" or "dynamic" counterpressure, the latter achieved by circulating the permeate co-current to the retentate to maintain an equal transmembrane pressure profile along the filtering path. Results showed that the controlled transmembrane pressure mode of operation was appropriate for conducting skimmed milk filtration, since it prevented from sharp increase of the hydraulic resistance of fouling and maintained nearly constant performances (permeability, selectivity) over the course of the time. In order to determine the more appropriate counter pressure mode and to predict skimmed milk performances, a four step method was proposed : i) assessment of the critical ratio; ii) selection of the critical flux at the required wall shear stress; iii) determination of the corresponding critical transmembrane pressure in "dynamic" counter-pressure; iv) calculation of the MF performance in "static" mode taking into account the gradient of transmembrane pressure induced by the retentate pressure drop.
\end{abstract}

hydrodynamics / crossflow microfiltration / operating mode / critical permeation flux / milk

\section{INTRODUCTION}

Separation and concentration of casein micelles from soluble proteins of skimmed milk can be achieved by crossflow microfiltration, $\mathrm{MF}$, using a $0.1 \mu \mathrm{m}$ mean pore diameter. During skimmed milk MF the fouling, mainly due to a deposit of casein micelles at the membrane surface, is dependent on a critical permeation flux, Jcrit, to wall shear stress, $\tau_{\mathrm{w}}$ ratio $[2,5]$. Under this critical ratio the performance (permeability

\footnotetext{
* Correspondence and reprints. gesan@labtechno.roazhon.inra.fr
} 
and selectivity) are satisfactory: long MF time with slow increase of fouling and high soluble protein transmission. The permeation flux, J governs convective mass transport to the membrane and $\tau_{\mathrm{w}}$ rules the transport by erosion, hydrodynamic diffusion or "lateral migration" of molecules and particles back from the membrane towards the fluid bulk $[1,3,7]$. The critical ratio can be determined in different ways: (i) with "parametric" experiments consisting of gradual increase of $J$ at constant $\tau_{w}$ [6] (the highest value for which the transmembrane pressure, $\Delta \mathrm{P}$ is stable is the critical flux, defined as the flux under which there is no deposition [4]) or of gradual decrease of $\tau_{w}$ at constant $\mathrm{J}$ or $\Delta \mathrm{P}$ [2] (the critical ratio is characterised by a sharp increase in the overall hydraulic resistance, $\mathrm{R}$ and decrease in protein transmission); (ii) with several experiments performed with constant $\mathrm{J}$ and $\tau_{\mathrm{w}}$ over the course of the time [5]: the limit between steady and "unsteady" (sharp increase in the overall hydraulic resistance) runs defined the critical ratio. The knowledge of the critical ratio enables the operator to determine optimal stable filtration operating conditions for high productivity, low processing costs and minimum cleaning requirements.

However the choice of the modes of operation (controlled $\Delta \mathrm{P}$ or J, "static" or "dynamic"1 counter-pressure) and the operating parameters $\left(\Delta \mathrm{P}\right.$ or $\left.\mathrm{J}, \tau_{\mathrm{w}}\right)$ is generally done without reference to the critical parameter. The aim of this paper is to show the impact of the critical ratio on MF processing and how to take it into account so as to give objective elements for the selection of the most appropriate start-up procedure and stationary mode of operation.

1 The "dynamic" counter-pressure is achieved by circulating the permeate co-current to the retentate to maintain an equal transmembrane pressure profile along the filtering path [8].

\section{MATERIALS AND METHODS}

\subsection{Fluids}

Skimmed milk, heat treated at $63{ }^{\circ} \mathrm{C}$ for $15 \mathrm{~s}$, was provided by Compagnie Laitière Européenne (Montauban-de-Bretagne, France). It was heated to $50{ }^{\circ} \mathrm{C}$ for $30 \mathrm{~min}$ before MF experiments and $0.2 \mathrm{~g} \cdot \mathrm{L}^{-1}$ sodium azide was added to it to prevent any micro-organism development. The cleaning solutions and water used as well as the cleaning procedures were previously described [3].

\subsection{Membranes and microfiltration rig}

The membranes were multichannel tubular ceramic Kerasep membranes with a $0.1 \mu \mathrm{m}$ mean pore diameter (7 channels, alumina membrane on an alumina support, Orelis, Miribel, France). Two membranes of different lengths were used: 0.400 or $0.856 \mathrm{~m}$ long, inner diameter $4.33 \pm 0.05$ or $4.35 \pm 0.0510^{-3} \mathrm{~m}$ and membrane area 0.037 or $0.081 \mathrm{~m}^{2}$ respectively. The hydraulic resistances of the 2 cleaned membranes were similar: $\mathrm{Rm}=1.4 \pm 0.2 \times 10^{11} \mathrm{~m}^{-1}$. Previous experiments have shown that the performance during skimmed milk MF were independent of the length of the membrane $(0.400$ or $0.856 \mathrm{~m})$ [3].

The MF rig [2] could operate at various concentrations of the feed stream using a feed-and-bleed mode, at controlled either $\mathrm{J}$ or $\Delta \mathrm{P}$. It was also equipped with the circulation of the permeate co-current to the retentate which allowed the experiments with simultaneous high $\tau_{\mathrm{w}}$ and low $\Delta \mathrm{P}$ to be performed.

\subsection{Operating procedures}

Every experiment was divided into two phases: a "concentration" phase, similar and reproducible (variation of $\mathrm{R}<10 \%$ ) for all the experiments and a "stepwise" phase or "time" phase. The skimmed milk was filtered at $50{ }^{\circ} \mathrm{C}$. 
- The "concentration" phase, already described [2], was conducted at a volume reduction ratio, $\mathrm{VRR}=2.0$, value chosen according to industrial use. It was conducted with $\tau_{\mathrm{w}}(150 \mathrm{~Pa})$, retentate pressure, $\mathrm{Pr}$ $\left(4.0 \times 10^{5} \mathrm{~Pa}\right)$ and constant $\mathrm{J}\left(91 \mathrm{~L} \cdot \mathrm{h}^{-1} \cdot \mathrm{m}^{-2}\right)$ or $\Delta \mathrm{P}\left(0.1 \times 10^{5} \mathrm{~Pa}\right)$. In both modes of operation (constant $\mathrm{J}$ or $\Delta \mathrm{P}$ ) a $\Delta \mathrm{P}$ of $0.1 \times 10^{5}$ $\mathrm{Pa}$ corresponded to a mean value of permeation flux of $91 \mathrm{~L} \cdot \mathrm{h}^{-1} \cdot \mathrm{m}^{-2}$ during the "concentration" phase. Once VRR reached the value of 2.0, VRR was maintained as constant by running MF in a feed-and-bleed mode of operation. After this phase of about $45 \mathrm{~min}$, the evolution of irreversible adsorption could be considered as negligible.

- The "stepwise" phase consisted of gradual increases of $\Delta \mathrm{P}\left(0.0-1.0 \times 10^{5} \mathrm{~Pa}\right)$ at constant $\tau_{\mathrm{w}}$, with $15 \mathrm{~min}$ duration at each step $\left(\tau_{\mathrm{w}}=100 \mathrm{~Pa}, \operatorname{Pr}=4 \times 10^{5} \mathrm{~Pa}\right)$. Points shown in the charts are the average values of $\mathrm{J}$ at the steady state during the step.

- The "time" phase consisted of experiment performed in the course of the time $\left(\tau_{\mathrm{w}}=100 \mathrm{~Pa}, \operatorname{Pr}=4 \times 10^{5} \mathrm{~Pa}\right)$ at either constant $\mathrm{J}$ (ranging from 38 to $76 \mathrm{~L} \cdot \mathrm{h}^{-1} \cdot \mathrm{m}^{-2}$ ) or $\Delta \mathrm{P}$ (ranging from $0.07 \times 10^{5}$ to $0.47 \times 10^{5} \mathrm{~Pa}$ )

Three start-up procedures performed at constant $\Delta \mathrm{P}$ were tested. The reference was performed without exceeding the set-up value of $0.1 \times 10^{5} \mathrm{~Pa}$, the other 2 exceeded the set-up value with a maximum $\Delta \mathrm{P}$ of 0.3 and $0.5 \times 10^{5} \mathrm{~Pa}$ for about $200 \mathrm{~s}$.

Some filtration experiments were performed in duplicate with a good reproducibility $(<5 \%$ for permeation flux and protein transmission).

\subsection{Calculations}

\subsubsection{Hydraulic resistances of membrane and fouling layers}

According to Darcy's law,

$$
\mathrm{J}=\frac{\Delta \mathrm{P}}{\mu \mathrm{R}}
$$

where $\mu$ is the dynamic viscosity (taken as $0.55 \times 10^{-3} \mathrm{~Pa} \cdot \mathrm{s}$ (water) and $0.60 \times 10^{-3}$ $\mathrm{Pa} \cdot \mathrm{s}$ (milk MF permeate) at $50{ }^{\circ} \mathrm{C}$ ), $\mathrm{R}$ is the overall hydraulic resistance which is broken down to:

$$
\mathrm{R}=\mathrm{Rm}+\mathrm{Rif}+\mathrm{Rrf}
$$

Rif, hydraulic resistance due to irreversible fouling (adsorption, internal pore blocking, etc.) on the membrane surface or in the membrane matrix.

Rrf, hydraulic resistance due to reversible phenomena (concentration polarization and/or reversible deposit).

$\mathrm{Rm}$ and Rif were calculated from different $\Delta \mathrm{P}$ values corresponding to pure water permeation fluxes (between 0 and $500 \mathrm{~L} \cdot \mathrm{h}^{-1} \cdot \mathrm{m}^{-2}$ ) before and after the milk MF respectively.

\subsubsection{Wall shear stress, $\tau_{w}$}

$\tau_{\mathrm{w}}$ which represents the forces applied by the fluid flowing tangentially to the membrane on an element of membrane area, was experimentally determined according to:

$$
\tau_{\mathrm{w}}=\frac{\mathrm{d} \Delta \mathrm{P}_{\mathrm{L}}}{4 \mathrm{~L}}
$$

where L, the length of the tubular membrane. The pressure drop along the filtering path, $\Delta \mathrm{P}_{\mathrm{L}}$, that should be used is that due to the flow through the filter tube. Bernouilli's equation was then used to calculate the longitudinal pressure drop along the membrane tube once the pressure losses due to recirculation of flow before and after the filter was removed from the measured value of pressure drop. For the experiments, d was taken equal to the initial diameter of the clean membrane. Due to the small variation of d over the course of the time during these experiments $(\Delta \mathrm{d}<3 \%), \tau_{\mathrm{w}}$ was considered as constant and is given with a $7 \%$ error.

The efficient wall shear stress, $\tau_{\text {weff }}$ was defined as:

$$
\tau_{\text {weff }}=\tau_{\mathrm{w}}-\tau_{\mathrm{wc} 0}
$$


with $\tau_{\mathrm{wc} 0}$, the critical erosion shear stress, under which, at $\mathrm{J}=0 \mathrm{~L} \cdot \mathrm{h}^{-1} \cdot \mathrm{m}^{-2}$, there is no transport of particles away from the deposit. $\tau_{\mathrm{wc} 0}$ depends on the membrane and the solution to be filtered.

\subsubsection{Selectivity}

Transmission, Tr was calculated as follows:

$$
\mathrm{Tr}=\frac{\mathrm{Cp}}{\mathrm{Cr}}
$$

with $\mathrm{Cp}$, concentration of the component at the outlet of the membrane pores and $\mathrm{Cr}$, concentration of the component in the retentate. $\mathrm{Cp}$ was calculated from the concentration of two samples withdrawn at the outlet of the permeate compartment at $t$ and $t+\Delta \mathrm{t}$ respectively. The calculation of $\mathrm{Cp}$ (at $t+$ $1 / 2 \Delta \mathrm{t}$ ) was then performed considering the permeate compartment to be a perfectly stirred compartment.

\subsection{Analyses}

Skimmed milk, permeate and retentate samples withdrawn during MF were analysed for $\alpha$-lactalbumin ( $\alpha$-LA) and $\beta$-lactoglobulin $(\beta-\mathrm{LG})$ contents (error $=2 \%$ ) by reverse phase high pressure liquid chromatography [2]. The turbidity (Turbidimeter, Hach, Namur, Belgium) of the permeate (error $=5 \%)$ characterised the transmission of the casein micelles through the membrane. Density (error $=0.2 \%$ ) was determined using a density meter (DMA 48, AP PAAR, Austria), and the dynamic viscosity of fluids (error $=1 \%$ ) using a microviscosimeter (D8, Haake, Karsruhe, Germany).

\section{RESULTS AND DISCUSSION}

\subsection{Performance of skimmed milk MF}

As previously described [5], the performance of the skimmed milk MF is mainly ruled by a deposit composed of retained casein micelles, micro-organisms and soluble proteins at the membrane surface. $\Delta \mathrm{P}$, $\mathrm{J}$ and $\tau_{\mathrm{w}}$ have been shown to play a major part in MF performance critical zone: when the balance between the convective forces (J) and crossflow $\left(\tau_{\mathrm{w}}\right)$ is tipped even slightly $\left(\mathrm{J} / \tau_{\mathrm{w}}>\left(\mathrm{J} / \tau_{\text {weff }}\right)_{\text {crit }}\right)$, the deposit becomes more and more consolidated and irreversible due to its compression under high $\Delta \mathrm{P}$ (that leads to increases in $\mathrm{R}$ and soluble protein retention) [2]. Le Berre and Daufin [5] showed that during skimmed milk MF the higher VRR the lower Jcrit. The insertion of VRR (effect of protein concentration) in the critical ratio was proposed (J. VRR $/ \tau_{\mathrm{w}}$ ) but this result remains to be confirmed not only with 2 VRR values as done previously [5] but by using a large range of VRR.

The performance of skimmed milk MF were characterised using "stepwise" experiments [4] and "time" experiments, all of them performed with "dynamic" counterpressure mode of operation. Whatever the methodology, the critical zone [2] and the performances (permeability, selectivity) were similar (Fig. 1). Figure 1 shows the performance obtained, for one "stepwise" experiment $J=f(\Delta P)$, one constant J "time" experiment, and 4 constant $\Delta \mathrm{P}$ "time" experiments. The evolution of the performance versus $\Delta \mathrm{P}$ showed 3 main steps: when $\Delta \mathrm{P}$ $<0.15 \times 10^{5} \mathrm{~Pa}, \mathrm{~J}=\mathrm{f}(\Delta \mathrm{P})$ was linear and the protein transmissions were high and relatively stable $\left(\operatorname{Tr}_{\alpha-\mathrm{LA}}=1.00-0.90 ; \operatorname{Tr}_{\beta-\mathrm{LG}}\right.$ $=0.90-0.80)$; the evolution of $\operatorname{Tr}_{\alpha-\mathrm{LA}}$ versus $\Delta \mathrm{P}$ (not shown) was analogous to $\operatorname{Tr}_{\beta-L G}$ evolution (Fig. 1b). Over $\Delta \mathrm{P}=\Delta$ Plim $\approx 0.2 \times 10^{5} \mathrm{~Pa}, \mathrm{~J}$ stabilised at a limiting permeation flux, Jlim of about $76 \mathrm{~L} \cdot \mathrm{h}^{-1} \cdot \mathrm{m}^{-2}$, and protein transmissions decreased sharply $\left(\operatorname{Tr}_{\alpha-\mathrm{LA}}\right.$ from 0.90 to $0.67 ; \operatorname{Tr}_{\beta-\mathrm{LG}}$ from 0.80 to 0.55$)$. In the transition zone between $0.15 \times 10^{5} \mathrm{~Pa}$ and $\Delta$ Plim an increase in the thickness of the casein micelles deposit occurs [2] and therefore delimited Jcrit, defined as the flux under which there is no deposition. Jcrit was in the range 65 to $76 \mathrm{~L} \cdot \mathrm{h}^{-1} \cdot \mathrm{m}^{-2}$ (Fig. 1a). A more precise value 
Figure 1. Comparison of performances obtained with "stepwise" and "time" experiments.

a: Evolution of the permeation flux, J versus the transmembrane pressure, $\Delta \mathrm{P}$.

$\mathrm{b}$ : Evolution of the transmission of $\beta$-lactoglobulin, $\operatorname{Tr}_{\beta \text {-LG }}$ versus the transmembrane pressure, $\Delta \mathrm{P}$. $\square: \Delta \mathrm{P}=$ constant; $\boldsymbol{\Delta}: \mathrm{J}=$ constant $=78 \mathrm{~L} \cdot \mathrm{h}^{-1} \cdot \mathrm{m}^{-2}$ ४ $\mathrm{J}=\mathrm{f}(\Delta \mathrm{P})$.

Operating conditions: $\tau_{\mathrm{w}}=$ $100 \mathrm{~Pa}$, see text.
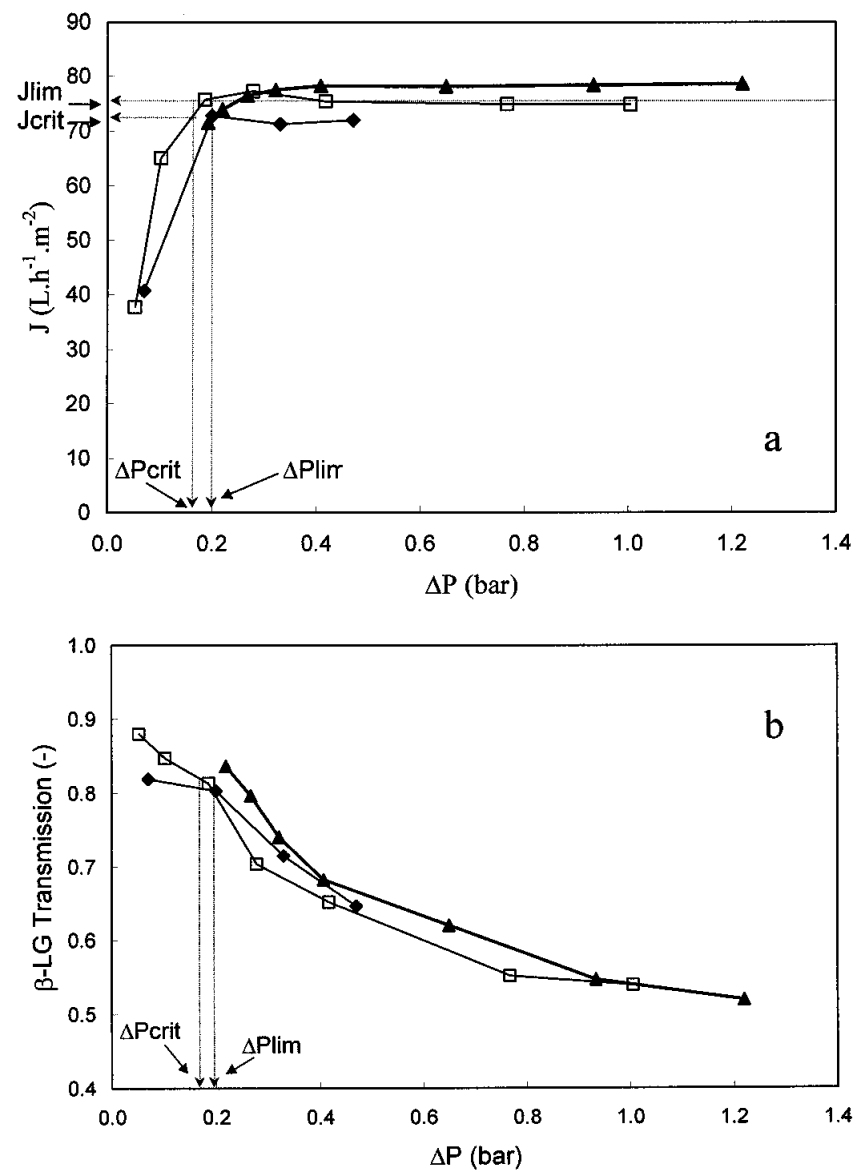

of Jcrit $\left(72 \pm 2 \mathrm{~L} \cdot \mathrm{h}^{-1} \cdot \mathrm{m}^{-2}\right)$ could be determined using "parametric" experiments $\Delta \mathrm{P}=$ $\mathrm{f}\left(\tau_{\mathrm{w}}\right)$ at constant $\mathrm{J}$ or $\Delta \mathrm{P}=\mathrm{f}(\mathrm{J})$ at constant $\tau_{w}[2]$. When operating at constant $\tau_{w}$ $\left(\tau_{\mathrm{w}}=100 \mathrm{~Pa}\right.$ in this work), Jcrit does become the appropriate criterion which must not be exceeded during the process in order to maintain high separation performance.

In order to characterise skimmed milk MF, one $2 \mathrm{~h}$ "stepwise" experiment appeared to be less time consuming than "time" experiments: 3 or 4 two hour "time" experiments were actually needed to get to the same information. The former methodology deserves consequently to be preferentially used for the characterisation of a system.

\subsection{Impact of the critical ratio on the selection of the operating mode}

\subsubsection{Constant J and $\Delta P$ modes of operation}

Under the critical ratio $\left(\left(\mathrm{J} / \tau_{\text {weff }}\right)_{\text {crit }}=\right.$ $\left.0.95 \mathrm{~L} \cdot \mathrm{h}^{-1} \cdot \mathrm{m}^{-2} \cdot \mathrm{Pa}^{-1} ; \tau_{\mathrm{wc} 0}=18 \mathrm{~Pa}\right)$ similar performances were observed whatever the operating modes ( $\mathrm{J}$ or $\Delta \mathrm{P}$ constant) in "time" experiments performed with "dynamic" mode: at constant $\tau_{\mathrm{w}}=100 \mathrm{~Pa}$ and $\mathrm{J}=38 \mathrm{~L} \cdot \mathrm{h}^{-1} \cdot \mathrm{m}^{-2}$ or $\Delta \mathrm{P}=0.07 \times 10^{5} \mathrm{~Pa}$ the normalised hydraulic resistance, $\mathrm{R} / \mathrm{Rm}$, was stable and equal to 7.5, $\operatorname{Tr}_{\alpha-\mathrm{LA}}=0.95$ and $\operatorname{Tr}_{\beta-L G}=0.83$ for $4 \mathrm{~h}$. 
Over the critical ratio MF performance depended on the mode of operation:

- at constant $\mathrm{J}$ a sharp increase in $\mathrm{R} / \mathrm{Rm}$ (Fig. 2a) and decrease in soluble protein transmission (Fig. 2b) were observed in contrast with constant $\Delta \mathrm{P}$ mode of operation.

- at constant $\Delta \mathrm{P}$ over $\Delta \mathrm{P}$ crit $\left(\approx 0.18 \times 10^{5} \mathrm{~Pa}\right.$, value required to get to Jcrit (Fig. 1a)), the performance were constant over the course of the time: $\mathrm{J}$ was equal to Jlim, that is to say the highest permeation flux that could be achieved under these operating conditions, and the permeate turbidity (which characterised the casein micelles retention) (35 NTU) and soluble protein transmission were constant over the course of the time. Increasing $\Delta \mathrm{P}$ led to stationary $\mathrm{J}=\mathrm{Jlim}$ and lower permeate turbidity but higher irreversible and protein transmissions
(Fig. 1b) indicating irreversible compression of the deposit formed at the membrane surface.

Thus operating at constant $\Delta \mathrm{P}$ prevented from sharp decrease in MF performance (permeability, selectivity) over the course of an experiment. Moreover, it is not worth working with higher $\Delta \mathrm{P}$, since it would result in increased protein retention and cleaning difficulties. The operating optimum of $\Delta \mathrm{P}$ was found to be $\Delta \mathrm{Pcrit}$, needed to get to Jcrit, which is close to Jlim (Fig. 1a). With $\tau_{\mathrm{w}}=100 \mathrm{~Pa}$ and $\Delta \mathrm{P}$ around $0.18 \times 10^{5} \mathrm{~Pa}$ MF performance reached a maximum in permeability for solvent $\left(\mathrm{J}=76 \mathrm{~L} \cdot \mathrm{h}^{-1} \cdot \mathrm{m}^{-2}\right)$ and soluble proteins $\left(\operatorname{Tr}_{\alpha-\mathrm{LA}}=0.95 ; \operatorname{Tr}_{\beta-\mathrm{LG}}=0.83\right)$. The determination of Jcrit (and thus $\Delta$ Pcrit) and variations of protein transmission of the system
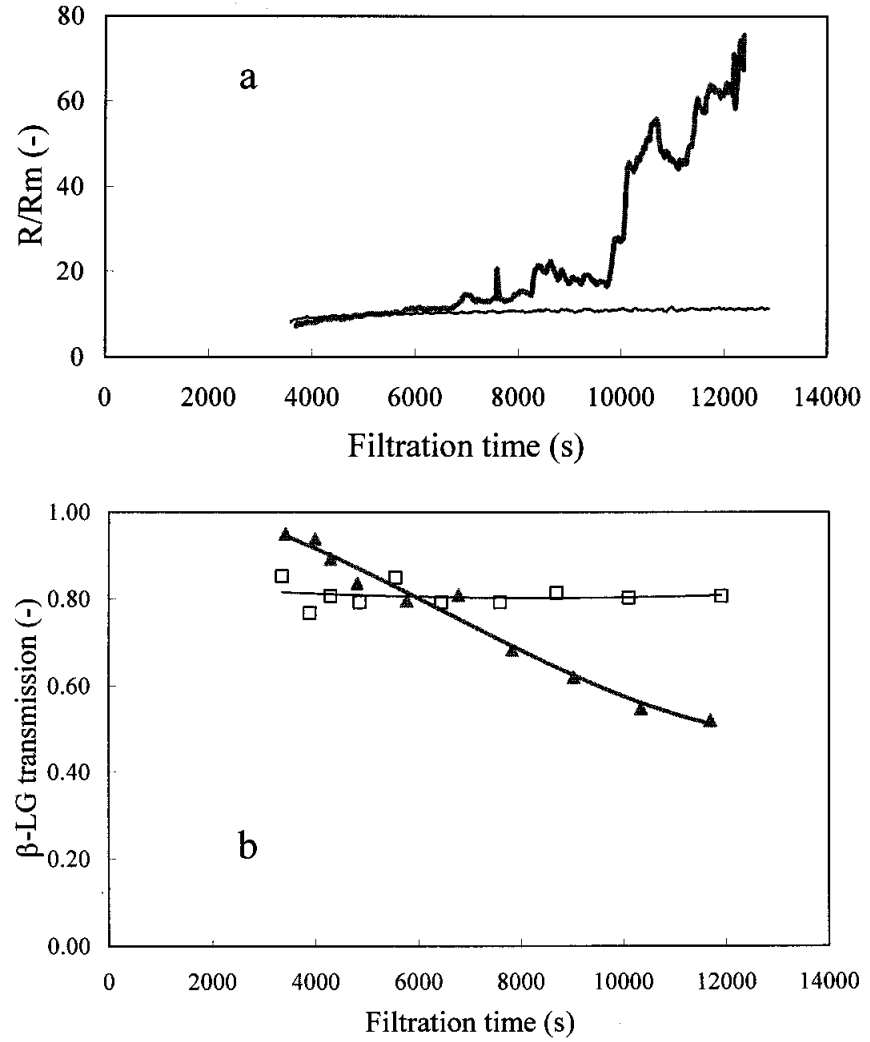

Figure 2. Comparison of performances obtained at constant permeation flux, $\mathrm{J}$, or constant transmembrane pressure, $\Delta \mathrm{P}$.

a: Evolution of the normalised overall hydraulic resistance, $\mathrm{R} / \mathrm{Rm}$ versus the filtration time.

- $\Delta \mathrm{P}=$ constant $=0.2 \times$ $10^{5} \mathrm{~Pa} ;-\mathrm{J}=\mathrm{J}=\mathrm{constan}$ $=76 \mathrm{~L} \cdot \mathrm{h}^{-1} \cdot \mathrm{m}^{-2}$

b: Evolution of the transmission of $\beta$-lactoglobulin, $\operatorname{Tr}_{\beta \text {-LG }}$ versus the filtration time.

$-\square-: \Delta \mathrm{P}=$ constant $=$ $0.2 \times 10^{5} \mathrm{~Pa} ; \longrightarrow \mathbf{\mathrm { A }}: \mathrm{J}=$ constant $=76 \mathrm{~L} \cdot \mathrm{h}^{-1} \cdot \mathrm{m}^{-2}$. Operating conditions: $\tau_{\mathrm{w}}=$ $100 \mathrm{~Pa}$, see text. 
using "stepwise" experiment were thus essential for the determination of optimal performances.

One can notice that in an industrial use operating at constant flux may be appropriate due to easiness to control especially when $\Delta$ Pcrit is very low (a few thousands of $\mathrm{Pa}$ ) as it is the case in skimmed milk MF. Jcrit must therefore not be exceeded in order to avoid sharp increase of fouling and short filtration duration.

\subsubsection{Start-up procedure}

With the 3 different start-up procedures performed using "dynamic" counter-pressure and constant $\Delta \mathrm{P}$ modes of operation the higher the exceeding of $\Delta \mathrm{P}$ (referred to $\Delta$ Pcrit $=0.18 \times 10^{5} \mathrm{~Pa}$ ), the higher the fouling $(\mathrm{R} / \mathrm{Rm}=7.0$ for no exceeding and 7.8 for a maximum $\Delta \mathrm{P}$ of $0.5 \times 10^{5} \mathrm{~Pa}$ after $1 \mathrm{~h}$ of filtration) and the lower the protein transmission $\left(\operatorname{Tr}_{\alpha-L A}=0.99\right.$ and $\operatorname{Tr}_{\beta-L G}=0.85$ for no exceeding and $\operatorname{Tr}_{\alpha \text {-LA }}=0.92$ and $\operatorname{Tr}_{\beta}-\mathrm{LG}=0.83$ for a maximum $\Delta \mathrm{P}$ of $0.5 \times$ $\left.10^{5} \mathrm{~Pa}\right)$. Exceeding $\Delta$ Pcrit $\left(=0.18 \times 10^{5} \mathrm{~Pa}\right)$ accompanied by transient $\mathbf{J}$ values above Jcrit resulted in the formation of an irreversible deposit at the membrane surface. The higher the exceeding the $\Delta \mathrm{P}$, the higher the compression of the deposit and the lower the filtration performance. The exceeding for $200 \mathrm{~s}$ was however short and perfor- mance very close to each other. Further experiments with longer exceedings of the $\Delta \mathrm{P}$ set-up value need therefore to be performed to confirm these trends and assess the robustness of the MF operation under severe variations of $\Delta \mathrm{P}$ control.

\subsection{3. "Static" and "dynamic" counter- pressure modes of operation}

According to the selected mean $\Delta \mathrm{P}$ significant or no significant differences in performances (always stable over the course of the filtration) could be observed between the 2 counter-pressure modes of operation.

At constant $\Delta \mathrm{P}=0.19 \times 10^{5} \mathrm{~Pa}$, close to $\Delta$ Pcrit, the "dynamic" counter-pressure led to better performance than the "static" mode: higher $\mathbf{J}$ and higher protein transmissions (Tab. I). At a higher $\Delta \mathrm{P}=0.47 \times 10^{5} \mathrm{~Pa}$, far over $\Delta$ Pcrit, "static" and "dynamic" modes led to similar $\mathrm{J}\left(\mathrm{J}=\mathrm{Jlim}=76 \mathrm{~L} \cdot \mathrm{h}^{-1} \cdot \mathrm{m}^{-2}\right)$ but lower protein transmissions were obtained in "dynamic" mode (Tab. I).

The results obtained in "static" mode could have been interpreted and predicted from the evolution of the performance (permeability, selectivity) versus $\Delta \mathrm{P}$ obtained in "dynamic" mode (Fig. 3). From the retentate pressure drop along the membrane in the retentate side, $\Delta \mathrm{P}_{\mathrm{L}}$ for a given $\tau_{\mathrm{w}}\left(\Delta \mathrm{P}_{\mathrm{L}}=\right.$ $0.38 \times 10^{5} \mathrm{~Pa}$ at $\tau_{\mathrm{w}}=100 \mathrm{~Pa}$ for the $0.400 \mathrm{~m}$

Table I. Comparison between experimental (Exp) and calculated (Calc) values of permeation flux ( $\mathrm{J})$, transmission of $\beta$-lactoglobulin $\left(\operatorname{Tr}_{\beta-\mathrm{LG}}\right)$ and $\alpha$-lactalbumin $\left(\operatorname{Tr}_{\alpha-\mathrm{LA}}\right)$, in "static" and "dynamic" counter-pressure modes of operation.

\begin{tabular}{|c|c|c|c|c|c|c|}
\hline & \multicolumn{3}{|c|}{$\Delta \mathrm{P}=0.19 \times 10^{5} \mathrm{~Pa}$} & \multicolumn{3}{|c|}{$\Delta \mathrm{P}=0.47 \times 10^{5} \mathrm{~Pa}$} \\
\hline & $\underset{\mathrm{L} \cdot \mathrm{h}^{-1} \cdot \mathrm{m}^{-2}}{\mathrm{~J}}$ & $\operatorname{Tr}_{\beta-\mathrm{LG}}$ & $\operatorname{Tr}_{\alpha-L A}$ & $\underset{\mathrm{L} \cdot \mathrm{h}^{-1} \cdot \mathrm{m}^{-2}}{\mathrm{~J}}$ & $\operatorname{Tr}_{\beta-\mathrm{LG}}$ & $\underset{-}{\operatorname{Tr}} \underset{-L A}{ }$ \\
\hline “dynamic" Exp & 76 & 0.82 & 0.94 & 76 & 0.66 & 0.77 \\
\hline "static" Exp & 55 & 0.74 & 0.85 & 76 & 0.70 & 0.85 \\
\hline "static" Calc & 53 & 0.77 & 0.90 & 76 & 0.67 & 0.80 \\
\hline "static" (Exp - Calc) / Exp (\%) & 4 & 4 & 6 & 0 & 4 & 6 \\
\hline
\end{tabular}

Experimental conditions: see text. 

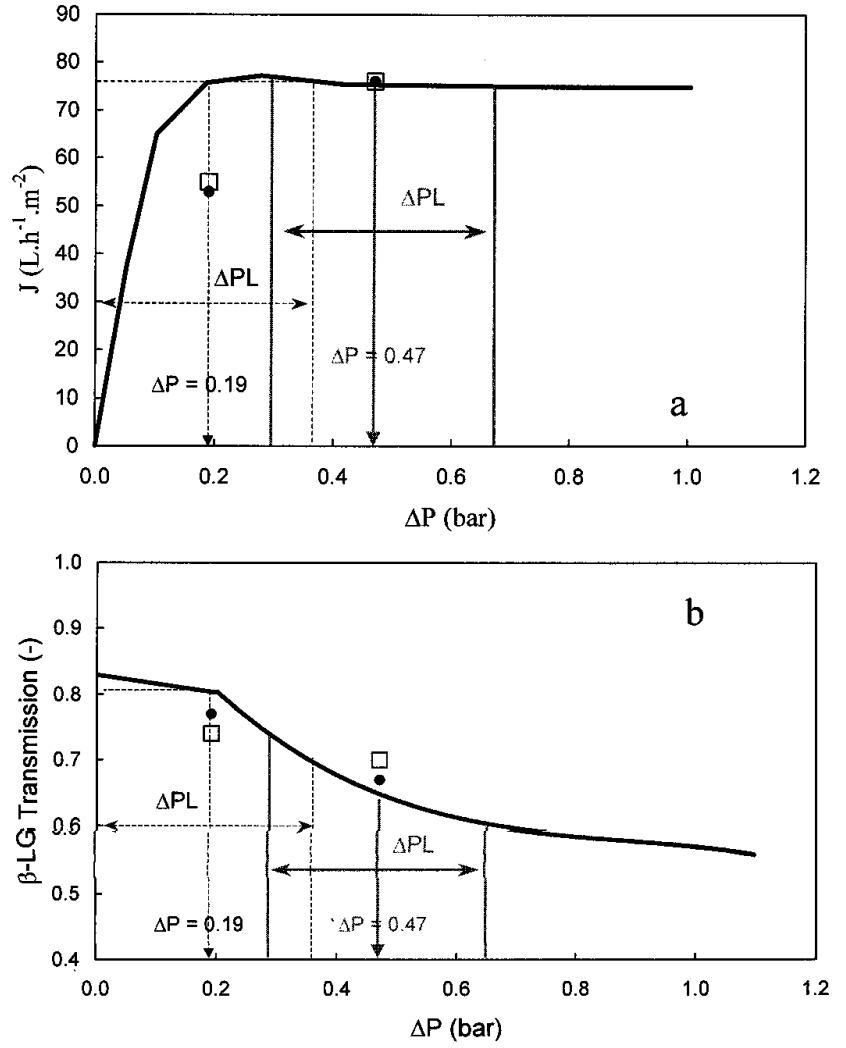

Figure 3. Basic principles for the prediction of performance in "static" counter-pressure mode of operation from data obtained in "dynamic" mode ( - ): comparison between experimental $(\square)$ and calculated $(\mathbf{O})$ values of permeation flux, $\mathrm{J}$ and transmission of $\beta$-lactoglobulin, $\operatorname{Tr}_{\beta-L G}$ in "static" mode.

$\Delta \mathrm{P}_{\mathrm{L}}$ is the retentate pressure drop generated along the membrane by shear stress, $\tau_{\mathrm{w}}=100 \mathrm{~Pa}$.

a: Evolution of J versus the transmembrane pressure, $\Delta \mathrm{P}$.

b: Evolution of $\operatorname{Tr}_{\beta-L G}$ versus $\Delta \mathrm{P}$.

- - - : Case $1 \Delta \mathrm{P}=0.19 \times$ $10^{5} \mathrm{~Pa} ;-$ : Case $2 \Delta \mathrm{P}=$ $0.47 \times 10^{5} \mathrm{~Pa}$.

Operating conditions: see text. long membrane) one can determine $\Delta \mathrm{P}$ in any area of the membrane from Figure 3. By integrating the evolution of performance (J (Fig. 3a) and protein transmissions (Fig. 3b)) along the filtering path (calculation of the area under the experimental curves obtained in "dynamic" mode (Fig. 3)), the expected average performance in "static" mode could be calculated from data obtained in "dynamic" mode. The calculated and experimental values obtained in "static" mode were in fairly good agreement $(<6 \%)$ (Tab. I, Fig. 3). At constant $\Delta \mathrm{P}=0.19 \times 10^{5} \mathrm{~Pa}$ performance obtained in "static" mode were worse than performance obtained in "dynamic": in "static" mode the membrane operated partially at low $\Delta \mathrm{P}$ corresponding to $\mathrm{J}<\mathrm{Jlim}$ and partially at high $\Delta \mathrm{P}$ corresponding to lower pro- tein transmission. At a higher $\Delta \mathrm{P}=0.47 \times$ $10^{5} \mathrm{~Pa}$ the membrane operated totally at a constant $\mathrm{J}=$ Jlim both in "static" and "dynamic" modes, but better protein transmissions in "static" than in "dynamic" mode were predicted due to the non-linearity of protein transmission versus $\Delta \mathrm{P}$ (Fig. 3b).

According to these results obtained with $\tau_{\mathrm{w}}$ as high as $100 \mathrm{~Pa}$ the "dynamic" counterpressure mode must be used at a $\Delta \mathrm{P}$ slightly smaller than $\Delta$ Pcrit for maximum protein transmission. In "static" mode, the large pressure drop along the filtering path, $\Delta \mathrm{P}_{\mathrm{L}}=$ $0.38 \times 10^{5} \mathrm{~Pa}$ to be compared to $\Delta \mathrm{Pcrit}=$ $0.18 \times 10^{5} \mathrm{~Pa}$ did not make it possible to work in optimal conditions for every area of the filtering path. Selecting a mean $\Delta \mathrm{P}$ significantly lower than $\Delta \mathrm{Pcrit}$ (for example 
down to half the $\Delta \mathrm{P}_{\mathrm{L}}$ ) in "static" mode will yield lower performance (lower $\mathbf{J}$ and protein recovery) due to a reverse permeation at the outlet part of the membrane $(\Delta \mathrm{P}<0)$.

Nonetheless, provided a decrease of $15 \%$ in protein transmission (compared to the maximum protein transmission obtained in "dynamic" mode) is acceptable from an industrial point of view, the "static" counterpressure mode of operation at a $\Delta \mathrm{P}$ higher than $0.2 \times 10^{5} \mathrm{~Pa}$ might be preferred (high permeation flux $(\mathrm{J}=\mathrm{Jlim})$, lower energetic costs).

These conclusions have to be drawn for any $\Delta \mathrm{P}_{\mathrm{L}}$ used since $\mathrm{MF}$ performance depends on the relative values of $\Delta \mathrm{P}_{\mathrm{L}}$ and $\Delta$ Pcrit.

Taking into account these results four steps are required for the selection of adequate operating conditions and counter-pressure mode of operation:

(i) The critical ratio $J / \tau_{w}$ must be determined using several "parametric" experiments $\Delta \mathrm{P}=\mathrm{f}\left(\tau_{\mathrm{w}}\right)$ at different constant J.

(ii) Knowing the retentate circulation pump capacity and acceptable energetic consumption, the required $\tau_{\mathrm{w}}$ can be selected, and consequently Jcrit determined.

(iii) The determination of the performance (permeability, selectivity) versus $\Delta \mathrm{P}$ using "stepwise" experiments at this constant $\tau_{\mathrm{w}}$ allows the adequate $\Delta$ Pcrit which must not be exceeded to be evaluated.

(iv) From the $\Delta \mathrm{Pcrit}$ value and $\Delta \mathrm{P}_{\mathrm{L}}$ induced by the required $\tau_{\mathrm{w}}$ the average performance (permeability, selectivity) can be calculated in "static" mode with a rather good precision owing to stable performance over the course of the time. The mode of counter-pressure ("static" or "dynamic") could therefore be selected for optimal process performance.

By using these basic principles, the analysis of the limits and advantages of both modes of operation is to be extended to several operating parameters taking into account the membrane geometry and fluid rheology (VRR, diafiltration rate, etc.) which both affect the retentate pressure drop along the filtering path. The analysis will be completed by taking into account the investment and processing costs.

\section{CONCLUSION}

For a system mainly ruled by a deposit of retained "species", the determination of the critical ratio $\left(\mathrm{J} / \tau_{\text {weff }}\right)_{\text {crit }}$ can be done easily using "parametric" studies. The determination of this ratio and of the global performance of the system (permeability and selectivity) versus permeation flux $\mathrm{J}$, transmembrane pressure $\Delta \mathrm{P}$ and wall shear stress, $\tau_{w}$ (in "dynamic mode") enable the optimal stable operating conditions and best modes of operation to be determined. The constant $\Delta \mathrm{P}$ mode is well appropriate (compared to constant $\mathrm{J}$ mode) for conducting filtration runs since it prevents from sharp decrease of performance, which occurs when Jcrit is tipped even slightly over the course of the time. The appropriate value of $\Delta \mathrm{P}$ corresponding to the value of Jcrit, close to Jlim, must be used and not exceeded even during the start-up procedures. The better understanding of the performances of a system versus $\Delta \mathrm{P}$ enables the appropriate counterpressure mode of operation either "static" or "dynamic" to be predicted. The basic principles one can use to determine the more appropriate counter-pressure mode with regard to the operation performance to be achieved are given in that paper. The analysis of the limits and advantages of both modes of operation are to be completed taking into account the investment and processing costs.

\section{REFERENCES}

[1] Barnier H., de Bank P., Crossflow microfiltration of amorphous $\mathrm{Fe}(\mathrm{OH})_{3}$ suspensions in high salt medium, ICIM'2, Congress Montpellier, July 1991, pp. 181-185. 
[2] Gésan-Guiziou G., Boyaval E., Daufin G., Critical stability conditions in crossflow microfiltration of skimmed milk: transition to irreversible deposition, J. Membrane Sci. 158 (1999) 211-222.

[3] Gésan-Guiziou G., Daufin G., Boyaval E., Le Berre O., Wall shear stress: effective parameter for the characterisation of the cross-flow transport in turbulent regime during skimmed milk microfiltration, Lait 79 (1999) 347-354.

[4] Howell J.A., Sub-critical flux operation of microfiltration, J. Membrane Sci. 107 (1995) $165-171$
[5] Le Berre O., Daufin G., Skimmilk crossflow microfiltration performance versus permeation flux to wall shear stress ratio, J. Membrane Sci. 117 (1996) 261-270.

[6] Madaeni S.S., The effect of operating conditions on critical flux in membrane filtration of latexes, Trans. I. Chem. En. Part B 75 (1997) 266-269.

[7] Samuelsson G., Huisman I.H., Tragardh G. Paulsson M., Predicting limiting flux of skim milk in crossflow microfiltration, J. Membrane Sci. 129 (1997) 277-281.

[8] Sandblom R.M.(Alfa-Laval) Filtering Process, Swedish Patent, 7416257 (1974).

\section{List of Symbols}

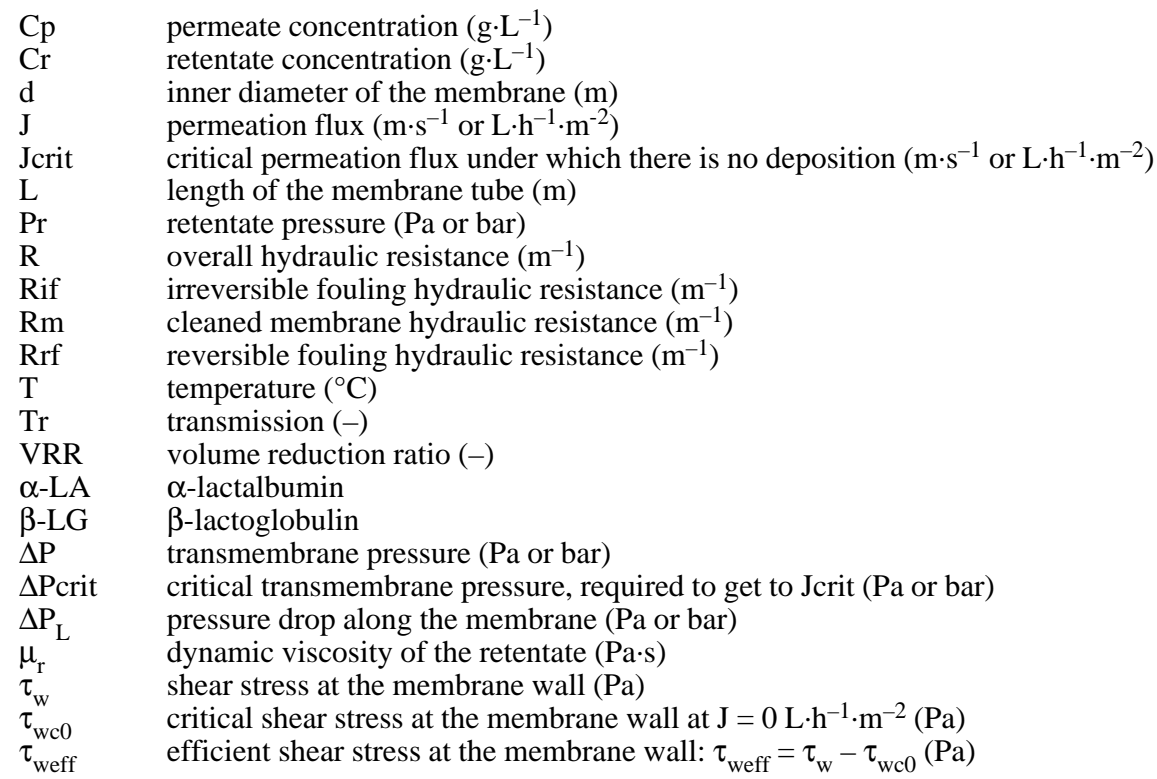

